\title{
Citizen involvement in flood risk governance: flood groups and networks
}

\author{
Clare Twigger-Ross ${ }^{1, a}$, Paula Orr ${ }^{1}$, Katya Brooks ${ }^{1}$ and Rolands Saduaskis ${ }^{1}$ \\ ${ }^{1}$ Collingwood Environmental Planning Ltd, 1E The Chandlery, 50 Westminster Bridge Rd, London SE17QY, UK
}

\begin{abstract}
Over the past decade has been a policy shift withinUK flood risk management towards localism with an emphasis on communities taking ownership of flood risk. There is also an increased focus on resilience and, more specifically, on community resilience to flooding. This paper draws on research carried out for UK Department for Environment Food and Rural Affairs to evaluate the Flood Resilience Community Pathfinder (FRCP) scheme in England. Resilience is conceptualised as multidimensional and linked to exisiting capacities within a community. Creating resilience to flooding is an ongoing process of adaptation, learning from past events and preparing for future risks. This paper focusses on the development of formal and informal institutions to support improved flood risk management: institutional resilience capacity. It includes new institutions: e.g. flood groups, as well as activities that help to build inter- and intra- institutional resilience capacity e.g. community flood planning. The pathfinder scheme consisted of 13 projects across England led by local authorities aimed at developing community resilience to flood risk between 2013 - 2015. This paper discusses the nature and structure of flood groups, the process of their development, and the extent of their linkages with formal institutions, drawing out the barriers and facilitators to developing institutional resilience at the local level.
\end{abstract}

\section{Introduction}

This paper focuses on understanding some of the barriers and facilitators to improving institutional resilience in the context of flood risk management in the UK with a specific focus on the role of flood groups and networks. Institutional resilience focuses on the development of formal and informal institutions to support improved flood risk management. Broadly, it refers to the governance of flood risk management. According to the concept of governance actors do not consist of exclusively government bodies but may include private sector business, community organisations, voluntary sector bodies and other NGOs, as well as influential individuals. The concept of multilevel governance suggests that governance takes place through processes and institutions operating at a variety of geographical scales, and includes a range of actors with different levels of authority [1]. Flood risk management in the UK has this type of governance structure, encouraged by the UK government concept of the "Big Society" together with a move to partnership funding for flood risk management. The former embraces localism and volunteerism. The latter encourages involvement of a wider range of actors at the local level. This also links to the wider narrative of adaptation to flooding, or "living with flooding" that has emerged over the past decade, in the UK, together with an increased focus on citizen engagement in all areas of civic life. However, a key question is: In what ways do these new structures e.g. flood groups, improve preparedness, response, and planning in relation to flooding. And if so how does that work? What are the pathways which lead to individuals and communities feeling and being more resilient to flooding? This paper focuses on flood groups and networks of flood groups, examining their potential role within the governance of flood risk. It draws on evidence from the Defra pathfinder scheme evaluation [2].

\section{Defining resilience}

The term 'resilience' has entered into common use within the world of disasters in general over the past two decades gaining increased prominence after Hurricane Katrina in 2005. It entered into UK government language on emergencies with the publication of the Civil Contingencies Act (2004) and the setting up of Local Resilience Forums. It came to prominence in relation to flooding after the UK 2007 floods [3] and was followed by a community resilience framework and guidance from UK government [4]. Although resilience has numerous definitions with varying emphases there is a consensus that it is a multi-faceted concept [5]. DFID [6] provides a

\footnotetext{
${ }^{\mathrm{a}}$ Corresponding author: c.twigger-ross@cep.co.uk
} 
useful definition from a disaster perspective that covers a number of the key aspects discussed within the literature:

\begin{abstract}
"Disaster resilience is the ability of countries, communities and households to manage change, by maintaining or transforming living standards in the face of shocks or stresses - such as earthquakes, droughts or violent conflict - without compromising their long-term prospects."
\end{abstract}

This definition together with the DFID model of disaster resilience draws out the multi-dimensional nature of resilience and highlights the possibility of transformation of communities so that risks can be better managed or lived with. Refining the definition further, the following definition is a useful articulation of what the flood resilience community pathfinders were aiming for within their projects:

"Communities working with local resources (information, social capital, economic development, and community competence) alongside local expertise (e.g. local emergency planners, voluntary sector, local responders) to help themselves and others to prepare and respond to, and to recover from emergencies, in ways that sustain an acceptable level of community functioning" [2]

This broadens the UK Cabinet Office definition to cover the whole risk management cycle (preparation, response and recovery) and focuses on what is important to maintain: a functioning community, everyday quality of life.

This definition also draws attention to the issue of capacities that exist within communities which provide the foundation for resilience within a disaster/emergency situation. Response and recovery is built using preexisting community capacities, which are expanded or extended in line with a - perhaps dramatically identified need [7]. Cutter et al [5, 8] call these capacities "inherent resilience". For the purposes of the evaluation, the Cutter et al $[5,8]$ framework was chosen because it is theoretically driven, whilst also being translated into measurable indicators:

This paper utilizes the inherent resilience portion of the disaster resilience of place (DROP) model (Cutter et al. 2008b) as its conceptual basis. The DROP model presented the relationship between vulnerability and resilience in a manner that is theoretically grounded and amenable to empirical testing. Furthermore, the DROP framework explicitly focused on antecedent conditions, specifically those related to inherent resilience. [5]

Five categories of community resilience are provided within the Cutter et al [5] paper $^{\mathrm{a}}{ }^{\text {social, economic, }}$

\footnotetext{
a It should be noted that in Cutter et al 2008 there is another category: ecological resilience but this was excluded "due to data inconsistency and relevancy when developing proxies for ecological systems resilience for large and diverse study areas". However, it is worth considering in future studies.
}

institutional and infrastructure resilience, community capital. These categories relate to how communities 'engage' with (i.e. prepare for, withstand, respond to, and recover from) disasters taking the view that: "Here resilience is as a set of capacities that can be fostered through interventions and policies, which in turn help build and enhance a community's ability to respond and recover from disasters" [5]. For the evaluation these categories have been interpreted into the specific context of flooding.

Social resilience: This category is based on the current and potential capability of individuals to engage with flooding within a community. For example, "communities with, fewer elderly, disabled residents, and non-native speaking residents likely exhibit greater resilience than places without these characteristics" [5]. These characteristics are some that have been shown to exacerbate negative impacts of flooding and links closely with work that has been carried out on social vulnerability in the context of flooding (see TwiggerRoss et al, 2014 for review [9]).

Community capital: This category focuses on the existing social networks and relationships within the local area. It "embodies what many refer to as social capital. We attempt to capture three key dimensions of social capital: sense of community, place attachment, and citizen participation" [5]. For example, knowing neighbours, informal help given / received and number of community groups belonged to. Evidence suggests this is the 'glue' that keeps communities together and provides the foundations upon which community flood resilience can be built. A key way in which social networks have been conceptualized is through the concept of 'social capital'. Putnam [10] has introduced the categories of bonding, bridging, and linking social capital to explain different types of social networks. 'Bonding' social capital describes the close bonds often based on familial or friendship ties. 'Bridging' social capital describes the looser networks between different people e.g. work colleagues, members of a sports club. 'Linking' social capital describes the hierarchical networks between people in local areas and organisations with power and influence. In the FRCP evaluation 'bonding' and 'bridging' social capital were considered under community capital, and 'linking' social capital under institutional resilience.

Economic resilience: This category refers to the economic vitality of both individuals and the community, including housing capital and ownership, equitable incomes, employment and business sustainability. For the purpose of the evaluation, the focus was on financial resilience, and in particular, on the availability and extent or cover of flood insurance, to enable individuals, and the communities of which they are part, to cope with the impact of flooding. Evidence shows that having greater financial resources can increase resilience to flooding.

Institutional resilience: The category is focussed on what institutional arrangements and experience are present within the community in relation to flooding. 
'Here, resilience is affected by the capacity of communities to reduce risk, to engage local residents in mitigation, to create organisational linkages and to enhance and protect the social systems within community $[5,11]$ Institutional resilience focuses on the development of institutions, both formal and informal to support improved flood risk management. It includes new institutions: e.g. flood group, flood group networks, and activities that help to build resilience within and between existing institutions e.g. multi-agency meetings, community flood plans, resilience groups within Parish councils. Broadly, it refers to the governance of flood risk management.

Infrastructure resilience: This category is 'mainly an appraisal of community response and recovery capacity and the extent to which physical infrastructures that house, transport and produce goods and services for society may be particularly vulnerable to sustaining damage and likely economic losses' [5]. This is taken together with any actions that communities take to increase their resilience to flooding through physical measures (e.g. property-level protection measures, flood storage, highway drainage).

The five resilience categories were used to develop indicators of community resilience to meet the research objectives of the evaluation and have helped the pathfinder projects to capture and describe their interventions within a framework of community resilience.

\section{Evaluating the Flood Resilience Community Pathfinder scheme}

The Flood Resilience Community Pathfinder scheme was intended to enable and stimulate communities at significant or greater risk ${ }^{\mathrm{b}}$ of flooding in England to work with key partners to develop innovative local solutions that:

-Enhanced flood risk management and awareness in ways which quantifiably improve the community's overall resilience to flooding.

-Demonstrably improve the community's financial resilience in relation to flooding.

-Delivered sustained improvements which have the potential to be applied in other areas.

Defra launched the scheme in December 2012, with an announcement that up to $£ 5$ million was being made available to fund up to 20 innovative projects between 2013 and 2015. It was open to all local authorities in England. There were 45 applications with projects submitted by 13 local authorities, from across England receiving funding. Figure 1 shows their locations.

\footnotetext{
${ }^{\mathrm{b}}$ Based on flood risk categories used in the UK National Flood Risk Assessment, significant risk equates to a one in 75 chance of flooding from rivers or the sea in any given year.
}

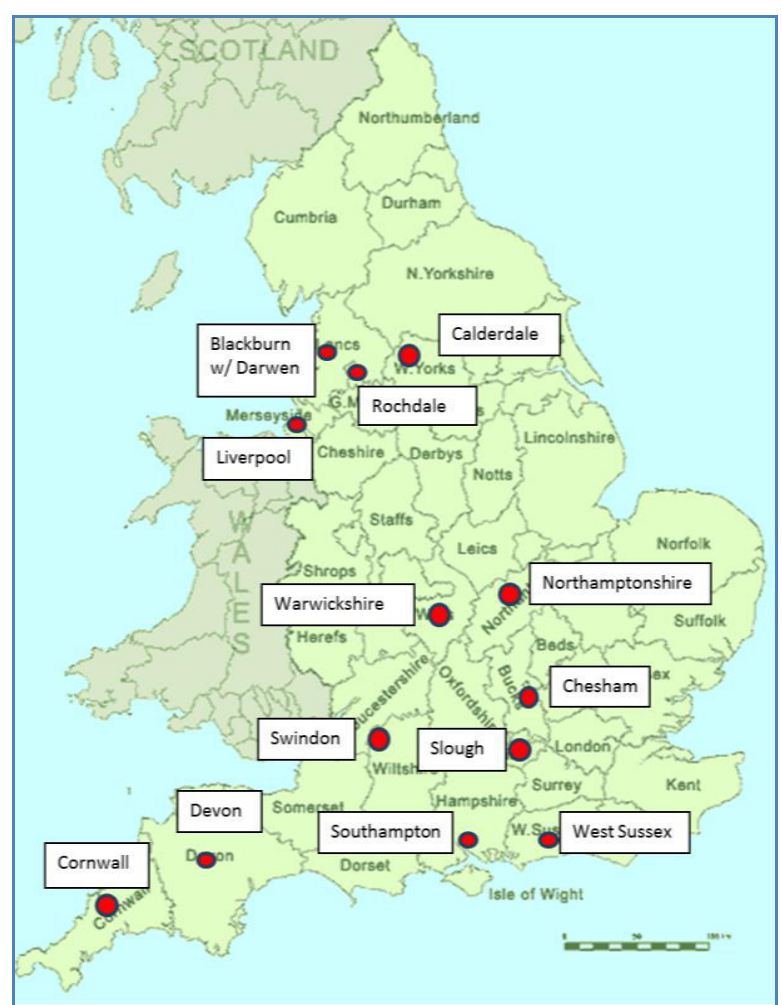

Figure 1 Location of Defra's 13 FRCP projects.

Source:www.picturesofengland.com

The pathfinder projects defined the boundaries of the communities they were working with. The scale varied from a few streets (Southampton) and a housing estate (Liverpool) through to part of a town or borough (Chesham, Swindon, Slough, Blackburn with Darwen, Calderdale, Rochdale) or a whole county (West Sussex, Cornwall, Devon, Warwickshire).

Each of the projects were led by local authorities and partnered by other organisations. The National Flood Forum (a national charity that works for flooded communities) was a partner in eight of the projects and other organisations involved included Environment Agency, England and Wales, Wildlife Trusts etc.

The purpose of the evaluation was to report on the progress made by the individual pathfinder projects, on the results and impacts of the scheme as a whole, and to provide evidence to ensure that lessons are learnt from the pathfinder scheme.

The evaluation questions were

-Did the pathfinder actions change people's behaviour in relation to managing flood risk?

-Did the characteristics of the areas or communities contribute to results?

-Which actions and combinations of actions made the most difference and were most sustainable?

-What economic benefits were generated?

-The potential for scale up and replication.

An experimental mixed methods approach using qualitative and quantitative social research techniques was used to collect, synthesise and analyse evidence for 
the evaluation at the baseline, interim (Year 1) and end of project (Year 2) stages. The evaluation drew on and incorporated a number of data sources (collected at the community and household levels) to provide information about the impacts and outcomes generated by the pathfinder projects as well as on implementation and process. Specifically, the following evidence was collected:

-Community baseline data - covering the five aspects of resilience at the community level

-Semi-structured interviews with project managers of the different pathfinders at Y1 and Y2

-Household survey - baseline and Y2 - covering the different aspects of community resilience

-Activity and output data -Y1 and Y2

- Case studies in specific areas of resilience

Qualitative data was analysed using a software package Dedoose.

\section{Findings}

The findings for this paper focus on institutional resilience. The activities, outputs and outcomes achieved are described first. This is followed by an analysis of the contribution of these activities to improving institutional resilience to flooding in the longer term.

All the pathfinders had work packages focussed on improving institutional resilience capacities. Two key activities carried out to improve institutional resilience were the:

-Development of flood groups and training and development of flood volunteers

-Development of relationships between members of the public and flood risk management authorities

\subsubsection{Flood groups and flood volunteers}

To begin with it is useful to be clear what is meant by a flood group. Given the wide variation in flood groups the evaluation used the following definition to capture the range of activities.

"anything from two active neighbours to a formal organisation and focussed on the following activities:

- Taking practical action in the locality to contribute to reduce flood risk - members of the group are visibly doing things

- Taking action to benefit neighbours/wider community, not just themselves

- Developing knowledge about local flood risk and its management

- Coordinating with agencies or organisations that may be relevant to reducing flood"'[2]

The table below shows the number of flood groups both maintained and developed during the time of the pathfinder scheme.

\begin{tabular}{|c|c|c|c|}
\hline Pathfinder & $\begin{array}{l}\text { Stated } \\
\text { aim to } \\
\text { create }\end{array}$ & $\begin{array}{l}\text { Groups in } \\
\text { existence } \\
\text { at the start } \\
\text { of the } \\
\text { project }\end{array}$ & $\begin{array}{l}\text { Total } \\
\text { number of } \\
\text { groups at } \\
\text { the end of } \\
\text { Year } 2 \\
\text { new and } \\
\text { maintained }\end{array}$ \\
\hline $\begin{array}{l}\text { Blackburn with } \\
\text { Darwen }\end{array}$ & $\mathrm{Y}$ & 0 & 5 \\
\hline Calderdale & $\mathrm{N}$ & 3 & 3 \\
\hline Chesham & $\mathrm{Y}$ & 0 & 1 \\
\hline Cornwall & $\mathrm{Y}$ & 30 & $30^{c}$ \\
\hline Devon & $\mathrm{N}$ & 11 & 24 \\
\hline Liverpool & $\mathrm{N}$ & 0 & 1 \\
\hline Northamptonshire & $\mathrm{N}$ & 0 & $11^{\mathrm{d}}$ \\
\hline Rochdale & $\mathrm{Y}$ & 0 & 1 \\
\hline Slough & $\mathrm{Y}$ & 0 & 3 \\
\hline Southampton & $\mathrm{Y}$ & 0 & 1 \\
\hline Swindon & $\mathrm{Y}$ & 0 & 3 \\
\hline Warwickshire & $\mathrm{Y}$ & 8 & 13 \\
\hline West Sussex & $\mathrm{Y}$ & 3 & 14 \\
\hline TOTAL & & 55 & $\begin{array}{l}111 \\
57 \text { new }\end{array}$ \\
\hline
\end{tabular}

Table 1: Number of flood groups

In terms of the process by which each project developed their groups, it varied depending on the type of area in which they were working. In areas where there had been recent flooding e.g. West Sussex, there was already some working going on with the National Flood Forum as a result of flooding in 2012 which meant that there was a base to start from whereas in Rochdale where there had been no flooding and little contact between the council and the community at risk.

Overall, the flood groups developed in ways that fitted the context in which they were situated. In terms of approach to community engagement, Successful approaches included:

-Starting where the community were (e.g. with residents groups, or from a flooding incident)

-Being flexible and responsive (e.g. able to change if one approach was not working)

-Putting in considerable effort in terms of building one to one relationships.

Groups varied in the formality of their structures, with some being formally constituted and others meeting on a more informal basis.

All pathfinders worked with volunteers ranging from those carrying out manual work e.g. leaf litter clearing through to more formal Flood Wardens, and all members of flood groups were volunteers. O'Brien et al [12]

\footnotetext{
${ }^{\mathrm{c}}$ Assumed no change: Cornwall did not focus on creating flood groups. Cornwall's Year 1 Project Report stated: 'The CCFF membership at the outset of pathfinder stood at $65^{\prime}$ ' but this includes groups and individuals. As Cornwall's initial Project Plan states that CCFF membership includes 30 parish/town councils, this figure was used

${ }^{\mathrm{d}}$ Northamptonshire pathfinder focussed on training flood wardens initially across their 15 communities but did also set up 11 community flood forums
} 
provide a useful classification of the activities carried out by flood volunteers:

-Knowledge focused: encompassing activities such as surveying a river in a catchment walkover, checking river gauges, monitoring water quality, pollution monitoring, collecting data as part of a citizen science project

-Campaign focused: for example raising awareness of flooding, taking part in flood planning, educational work with schools, and promoting the uptake of local flood warden services

-Physical focused: such as embankment building, habitat management, opening and closing sea gates, clearing drainage ditches and water courses

-Virtual focused: such as remote monitoring or webrelated action such as documenting the groups' activities and providing information on web pages.

In terms of the types of activities carried out, the predominant focus across the pathfinders was 'campaign focused', with all pathfinders carrying out some aspect of this. Key activities of the flood volunteers across pathfinders in this category were:

-Developing flood plans: e.g. Southampton's flood group which also planned a 'dry run' to test it out;

-Improving flood warning: e.g. Cornwall's use of telemetry in one community to provide alerts during periods of high intensity rainfall;

-Raising awareness of flooding across communities: e.g. Swindon's group running a flood awareness stall at local event.

There were specific pathfinders whose flood volunteers also focussed on knowledge gathering activities, for example: Cornwall's rain gauge at $\mathrm{St}$ Blazey; Warwickshire groups' use of CCTV to enable reporting of watercourse blockages; Blackburn with Darwen's 'gullywatch' group; and Rochdale's scout gully and river watch project. These knowledge gathering activities were closely linked to the campaign focused activities: for example, volunteers gathering data from, a rain gauge linking into providing a flood warning.

A number of pathfinders have had volunteers carrying out 'physical focused' activities: Cornwall's leaf litter clearing project; Calderdale's river stewardship events to remove Himalayan balsam; Rochdale's clean-up day.

Pathfinders whose volunteering had a virtual focus included Calderdale's website http://eyeoncalderdale.com/ which is a single source of information from the authorities dealing with flood risk but includes crowd-sourced mapping of flood related problems (e.g. gully blockages).

So what were the successful outcomes of flood groups and flood volunteers? The key outcomes can be grouped into three areas:

Firstly, learning by community members, and staff in local authorities and agencies in terms of:

-Knowledge and awareness of flood risk management: a key aspect of the flood groups was how far the members have developed their knowledge and awareness of flooding. The main outcome of campaign type volunteering was to increase knowledge of flood warnings and responses, to increase positive actions that could be taken in the event of a flood, to ensure there are plans that can be followed during a flood to reduce negative impacts for communities and specifically to support more vulnerable members of the community during a flood. Knowledge gathering activities support taking early action to prevent flooding in some cases as well as providing data over time on rainfall and other issues.

-Learning by institutions and members: a key aspect in relation to institutional resilience is that of the learning that has happened by both the groups and the institutions. There is evidence that this has happened across a number of pathfinders by all parties:

'As demonstrated by one of the flood action group's feeding their local knowledge into the modelling used in Swindon's local flood risk management strategy and Thames Water's Catchment Study in Swindon.' (Swindon pathfinder Year 2 Evaluation Report)[2]

Secondly, empowerment and development of networks in terms of:

- Confidence and voice of citizens to engage with key authorities: Having increased knowledge enabled members to engage with Agencies and local authorities and this gave them confidence to take part in those conversations and in so doing provided a voice for the community:

'It gives us a voice because the Flood Forum [] is set up to get all interested parties together to talk to each other. And it's not them and us, sort of thing. It's trying to work together as a partnership to solve a problem.' (Flood group member quoted in Swindon pathfinder Year 2 Evaluation Report)[2]

\section{-Increased bonds of trust between local community} members and institutions: Through regular engagement with agencies and authorities relationships and trust is being developed: 'At first many communities expressed their frustration on how complex flood risk management responsibilities and governance are locally. However, groups noticed that by regularly engaging with local authorities and agencies staff, two-way communications have improved and relationships have strengthened with the local community.' (Devon pathfinder Year 2 Evaluation Report)[2]

Finally a key outcome was the support flood groups gave people in communities to improve flood resilience. This was observed directly in two ways: 
-Support for property level protection: having a flood group has helped in a number of pathfinders to support the uptake of PLP. In Southampton specifically, the flood group really came together around PLP and procured it as a group with support from the local authority. The project manager for Southampton did not think the solution would have been as successful without the group.

-Flood groups helping people to avoid damages in a flood: crucially, with specific respect to impacts, is whether the flood groups can help people avoid damages within a flood. Southampton had a clear example of the flood group helping during the flood, by warning neighbours and moving cars as needed.

-Flood planning: 12 of the pathfinders carried out some form of community flood planning. This ranged from engaging people in developing individual flood plans through to flood groups carrying out 'dry runs' of emergency plans.

-Flood groups raising awareness: in a number of pathfinders the flood groups worked with local authorities to raise awareness (e.g. Calderdale, Swindon). This included giving talks and also running stands at events. The value of local input was recognized, having local people talking about flooding rather than just the agencies and authorities was seen as a benefit.

\subsubsection{Links between formal and informal structures: the role of networks}

A key aspect in relation to institutional resilience is to understand how links between the formal and informal institutions are becoming part of the formal structures of decision making. What can be observed is the extent to which the flood groups are more or less embedded within formal structures of decision making. Evidence suggests that having a clear role within wider decision making should improve the resilience of the flood groups and their relationships with institutions. The pathfinders vary in how far they have formal links with the local authorities. For some pathfinders' flood groups, whilst not having a formalised role with respect to flood risk management at the end of Year 2 they are considered by the project managers to be quite embedded within the flood risk management governance. Evidence of this can be seen in comments on the increased communications between local residents and the local authorities, together with an increased confidence and knowledge on the part of the residents to be able to contribute to the debate: 'What this has done is deepen the relationships. I wouldn't say enhanced, but given them more gravitas, because they've been given information and information is power. They've absorbed [information and experience from meetings], and I think that will make them stronger people in the future ... they won't be reluctant, they won't feel they're at the end of the line.' (Interview with a local councillor, Liverpool pathfinder Year 2 Evaluation Report) [2]
Warwickshire have reported how the input from the flood groups has been taken through into the LFRMS. With respect to 'embedded' this refers to those groups for whom a place is being developed within the decision making process. Examples of this were West Sussex and Cornwall. In West Sussex, the aim was to get representation from community groups onto the County Council's strategic flood risk management group. To do this, representatives have been chosen from the WSFAGF (West Sussex Flood Action Group Forum) which brings together all the flood groups into a network. This enables representation of local communities on the decision making group within the county.

The aims of the WSFAGF are:

- To encourage the establishment of the WSFAGF to ensure help towards Flood Action Group sustainability and provide peer support as a form of exit strategy within the pathfinder project;

-To provide transparency of how Risk Management Authorities manage flood risk in West Sussex and to provide communities with the opportunities to contribute to the process of FRM

The network started with an event to set up the network of 14 flood action groups in Jan 2015 and has had further meeting since that date. The other key aspect is the inclusion of representatives from the network on West Sussex Flood Strategic Flood Risk Management Board

In terms of outcomes the key ones are sharing learning between the different groups together with the representation of the community voice on formal structures.

"But the biggest thing that developed networks etc was bringing all the groups together that has really built resilience as people have shared ideas, examples. So bringing the group together across the county was a really big thing and developed networks.' (Interview $13 P M)[2]$

'There has been a real governance change, with members of the flood action group sitting on the Strategic Flood Risk Management group alongside the Risk Management Authorities - this has been a huge institutional change - to recognise the value of the community voice.' (Interview 13PM)[2]

\section{Evidence for improved institutional resilience?}

So can it be said that there is improved institutional resilience capacity? To begin with there is evidence of increased "linking capital" at local, regional and national levels. Specifically, the relationships of trust and were developed between citizens and people in positions of influence in relation to flood risk management. As well as this there are new structures and arrangements which have embedded some of these relationships in such a way that they should out last the individuals involved and move to more of a model of collaborative governance. 
Inevitably, there are still challenges. Firstly, there is still a need to understand full impact of these developments which will happen over time and for them to be tested in flood event.

Secondly, sustaining interest, knowledge and skills within the community as a key issue has been that flood groups often rely on a small number of people to make things happen. It was recognised that this can be quite a fragile structure, with careful consideration needed about what can be expected from members:

'However, it is also clear that this is a fragile resilience built on several layers of trust and ultimately reliant on a small number of key individuals.. .' (Cornwall pathfinder Year 2 Evaluation Report)[2]

Having project managers and community engagement specialists (e.g. National Flood Forum) involved in the pathfinder projects has been crucial to creating interest and maintaining momentum over the period of the project and their role cannot be underestimated.

This links thirdly to the sustainability of groups into the future without the pathfinder scheme support. However, a number of the projects have managed to get funding for more work going forward.

\section{References}

1. Hooghe, L. and Marks, G. (2003) Unravelling the central state, but how? Types of multi-level governance. American Political Science Review, 97(2): 233-243

2. Twigger-Ross, C., Orr, P., Brooks, K., Sadauskis, R., Deeming, H., Fielding, J., Harries, T., Johnston, R., Kashefi, E., McCarthy, S., Rees, Y., and Tapsell, S. (2015) Flood Resilience Community Pathfinder Evaluation Final report FD1664. London: Defra

3. Pitt, Sir Michael (2008) Learning lessons from the 2007 flooding. London: HMSO.

4. Cabinet Office (2011) National Strategic Framework for Community Resilience. Cabinet Office: UK Government

5. Cutter, S., Burton, C. and Emrich, C. (2010) Disaster resilience indicators for benchmarking baseline conditions, Journal of Homeland Security and Emergency Management, 7(1): 122

6. DFID (2011) Defining Disaster Resilience: A DFID Approach Paper. London: Department for International Development

7. Dynes, R.R. (2005) Community Social Capital as the Primary Basis for Resilience (\#327) University of Delaware, Disaster Research Center. http://dspace.udel.edu:8080/dspace/handle/1971 $\underline{6 / 1621 .}$
8. Cutter, S., Burton, C. and Emrich, C. (2010) Disaster resilience indicators for benchmarking baseline conditions, Journal of Homeland Security and Emergency Management, 7(1): 122

9. Twigger-Ross,C., Kashefi, E., Weldon, S., Brooks, K., Deeming, H., Forrest, S., Fielding, J., Gomersall, A., Harries, T., McCarthy, S., Orr, P., Parker, D., and Tapsell, S. (2014) Flood Resilience Community Pathfinder Evaluation: Rapid Evidence Assessment. London: Defra

10. Putnam, R.D. (2000) Bowling Alone: The Collapse and Revival of American Community. New York: Simon \& Schuster.

11. Norris, F.H., Stevens, S.P., Pfefferbauam, B., Wyche, K.F. and Pfefferbaum, R.L. (2008) 'Community resilience as a metaphor, theory, set of capacities, and strategy for disaster readiness', American Journal of Community Psychology, 41(1-2):127-150.

12. O'Brien, L., Ambrose-Oji, B., Morris, J., Edwards, D (2014) Civil society and flood resilience: Characterising flood risk volunteers and understanding motivations and benefits. Paper presented at the 20th Voluntary Sector and Volunteering Research Conference 2014, Sheffield Hallam University, Sheffield, September 10-11th 2014 